Article

\title{
The Development of CMOS Amperometric Sensing Chip with a Novel 3-Dimensional TiN Nano-Electrode Array
}

\author{
Chun-Lung Lien ${ }^{1}$ and Chiun-Jye Yuan ${ }^{1,2,3, *}$ \\ 1 Department of Biological Science and Technology, National Chiao Tung University, Hsinchu 30068, Taiwan; \\ andrew0958.bt99g@g2.nctu.edu.tw \\ 2 Institute of Molecular Medicine and Bioengineering, National Chiao Tung University, \\ Hsinchu 30068, Taiwan \\ 3 Center for Intelligent Drug Systems and Smart Bio-Devices (IDS2B), National Chiao Tung University, \\ Hsinchu 30010, Taiwan \\ * Correspondence: cjyuan@mail.nctu.edu.tw; Tel.: +886-3-5731735; Fax: +886-3-5729288
}

Received: 19 December 2018; Accepted: 22 February 2019; Published: 26 February 2019

\begin{abstract}
An electrochemical sensing chip with an $8 \times 8$ array of titanium nitride three-dimensional nano-electrodes (TiN 3D-NEA) was designed and fabricated via a standard integrated complementary metal oxide semiconductor process. Each nano-electrode in 3D-NEA exhibited a pole-like structure with a radius of $100 \mathrm{~nm}$ and a height of $35 \mathrm{~nm}$. The numeric simulation showed that the nano-electrode with a radius of around $100 \mathrm{~nm}$ exhibited a more uniformly distributed electric field and a much higher electric field magnitude compared to that of the microelectrode. Cyclic voltammetry study with $\mathrm{Ru}\left(\mathrm{NH}_{3}\right)_{6}{ }^{3+}$ also revealed that the TiN 3D-NEA exhibited a much higher current density than that obtained from the microelectrode by two orders of magnitude. Further studies showed that the electrocatalytical reduction of hydrogen peroxide $\left(\mathrm{H}_{2} \mathrm{O}_{2}\right)$ could occur on a TiN 3D-NEA-based sensing chip with a high sensitivity of $667.2 \mathrm{~mA} \cdot \mathrm{mM}^{-1} \cdot \mathrm{cm}^{-2}$. The linear detection range for $\mathrm{H}_{2} \mathrm{O}_{2}$ was between $0.1 \mu \mathrm{M}$ and $5 \mathrm{mM}$ with a lowest detection limit of $0.1 \mu \mathrm{M}$. These results indicated that the fabricated TiN 3D-NEA exhibited high catalytic activity and sensitivity to $\mathrm{H}_{2} \mathrm{O}_{2}$ and could be a promising sensor for $\mathrm{H}_{2} \mathrm{O}_{2}$ measurement.
\end{abstract}

Keywords: nano-electrode; CMOS; 3D Sensor; titanium nitride; hydrogen peroxide

\section{Introduction}

Electrochemical sensing technology has been widely adopted in the design of biosensors for clinical diagnosis and point-of-care (POC) testing due to its simple design, quick detection, and cost effectiveness [1]. Many methods have been developed to improve the electrochemical reactivity and sensitivity of electrodes, including anodic surface cleaning [2], surface modification [3,4], plasma treatment [5], and miniaturization [6-10]. Among these methods, miniaturization exhibits several advantages, including low power consumption, small sample volume requirement, high electrochemical responses, low electric noise, and portability. Small sample volume requirement is helpful in the development of biomedical devices for detecting rear or dangerous biological samples. When the electrode size is reduced to nano-scale, the diffusion becomes convergent to the surface of the electrode and enhances the mass transport of electroactive species to its surface [11-16]. Hence, the electrochemical responses on the nano-electrode may not be limited by the diffusion of electroactive species due to the high mass transport rate $[6,13,14]$. Accordingly, the responses on nano-electrodes may reflect the actual enzymatic activity or chemical reactions during the analysis. 
Electrode miniaturization may have some drawbacks, such as reduced total surface area, reduced biomolecule conjugation, and limited reactive sites. These problems may further lead to low electrochemical responses and quick saturation during detection. To increase the total surface area and reduce the influence of the miniaturization on the performance of electrodes, generating the electrode array [6-13,17-22] and/or forming the protruding nano-structures through post-fabrication modification [17,23-31] are usually adopted for the design of micro- and nano-electrodes. However, most of the reported micro- and nano-electrode arrays with or without protruding structures were fabricated by microelectromechanical system (MEMS)/nanoelectromechanical system (NEMS) or MEMS/NEMS integrated with the complementary metal oxide semiconductor (CMOS) technology. The integration of MEMS and CMOS processes opens up new possibilities in the design and development of various micro-sensors and electrodes. However, the need for dedicated manufacturing foundries, high cost, and limited choices of materials, design rules, and micromachining processes may be the limitations for the fabrication of sensors and actuators by integrating MEMS and CMOS fabrication technologies. With these limitations, the standard CMOS process may a good choice to generate sensors and electrodes with simple nano-configurations or three-dimensional (3D) nano-structures. With the standard CMOS process, the fabrication of nano-scaled electrodes can be controlled by the well-developed processes such as photolithography, chemical vapor deposition, and e-beam lithography. Hence, the mass production of nano-sensors with highly uniform 3D structure and well-defined geometry is feasible. However, the material suitable for the fabrication of the biosensing chip is limited in the standard CMOS process. Among materials frequently used in the CMOS process, titanium nitrite (TiN), a ceramic material, exhibits an excellent combination of chemical, physical, mechanical, and electrical properties such as high hardness, good chemical stability, abrasion and corrosion resistance, chemical inertness, high conductivity, and biocompatibility [23,32-35]. Most importantly, compared to $\mathrm{Au}, \mathrm{Pd}$, or $\mathrm{Pt}, \mathrm{TiN}$ is more cost-effective and less sticky to the reaction chambers without causing contamination. Accordingly, TiN is regularly used in the standard CMOS process for the fabrication of the CMOS devices $[24,36,37]$. Hence, even though the electric conductivity of TiN $\left(8.69 \times 10^{6} \Omega^{-1} \cdot \mathrm{m}^{-1}\right)$ is about $20.9 \%$ of that of gold $\left(4.17 \times 10^{7} \Omega^{-1} \cdot \mathrm{m}^{-1}\right)$, it is suitable for the fabrication of a sensing chip via the standard CMOS process.

In this work, an electrochemical sensing chip with TiN-based 3D nano-electrode array (TiN 3D-NEA) was proposed to be fabricated by the standard CMOS process. The 3D configuration can effectively increase the surface area of nano-electrodes, providing more space for bioconjugation and generating more reactive sites for reaction [11-13,17,38,39]. Subsequently, the redox responses and the electrochemical behavior of the fabricated CMOS 3D-NEA chip was investigated by cyclic voltammetry, and it was found that the 3D-NEA sensing chip exhibited a voltammetry response deviating from the conventional diffusion-controlled current flow. Furthermore, hydrogen peroxide $\left(\mathrm{H}_{2} \mathrm{O}_{2}\right)$ was found to be electrocatalytically reduced on the CMOS 3D-NEA sensing chip with high sensitivity and a wide linear range of detection.

\section{Materials and Methods}

\subsection{Materials}

Phosphate buffer solutions (PBS) with different $\mathrm{pH}$ were prepared from $0.1 \mathrm{M} \mathrm{KH_{2 }} \mathrm{PO}_{4}$ and $0.1 \mathrm{M} \mathrm{K}_{2} \mathrm{HPO}_{4}$. Ascorbic acid (AA), uric acid (UA), dopamine (DA), acetaminophen (AC), hexaammineruthenium (III) chloride $\left(\mathrm{Ru}\left(\mathrm{NH}_{3}\right)_{6} \mathrm{Cl}_{3}\right)$, and glucose were purchased from Sigma Aldrich. Ultra-pure water with resistance higher than $18 \mathrm{M} \cdot \mathrm{ohm} \cdot \mathrm{cm}$ was employed to prepare all solutions and electrolytes. All other reagents were analytical grade.

\subsection{Chip Design and Fabrication}

The sensing chip $(20 \mathrm{~mm} \times 20 \mathrm{~mm}$ ) containing 10 sensing units (Figure $1 \mathrm{~A}, \mathrm{D})$, which were connected to their own contact pads through connecting wires, was fabricated via a standard 
CMOS process in the National Nano Device Laboratories (NDL) at the Science-Based Industrial Park, Hsinchu, Taiwan.

A

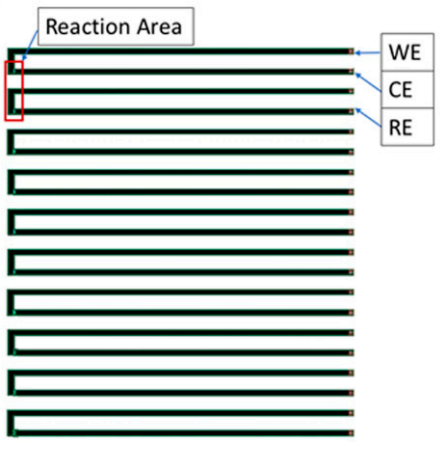

C

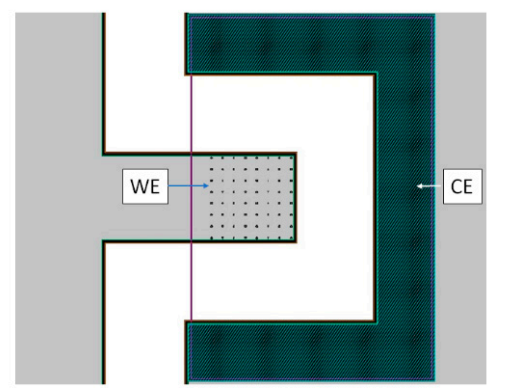

B

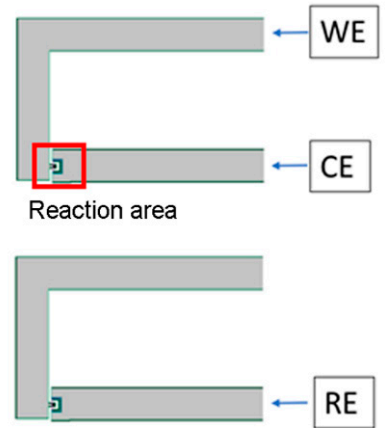

D

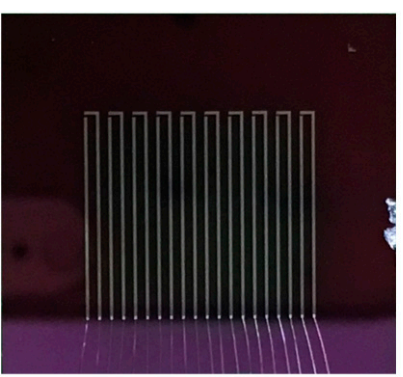

Figure 1. The complementary metal oxide semiconductor (CMOS) sensing chip with titanium nitride three-dimensional nano-electrodes (TiN 3D-NEA). (A) The sensing chip contains 10 units of working (WE) and counter electrodes (CE). (B) The enlarged reaction area of the electrode set in (A). The counter electrode of the adjacent electrode unit was used as the reference electrode (RE). (C) The diagram of an electrochemical sensing unit on the CMOS chip. Each sensing unit contained an $8 \times 8$ nano-electrode array as a WE and a CE. (D) The fabricated CMOS sensing chip $(20 \mathrm{~mm} \times 20 \mathrm{~mm}$ ) with bonding wires (bottom part).

The fabrication flow for 3D NEA is illustrated in Figure 2. Briefly, an 8-inch single crystalline silicon wafer (step 1) with a p-type (100)-oriented substrate that exhibited a resistance of $0.5-100 \Omega \cdot \mathrm{cm}$ and a thickness of $725 \mu \mathrm{m}$ was used for the fabrication of a sensing chip containing 3D NEA. The fabrication was started with the thermal oxidation of the silicon wafer to generate a $1500 \AA$ thick silicon dioxide substrate (step 2) for electrical isolation between the substrate and the surface. On the silicon dioxide, a $4000 \AA$ thick AlSiCu adhesion layer (step 3) as adhesive as well as conducting layer and a layer of $2000 \AA$ thick TiN (step 4) as an electrode material were sequentially deposited by physical vapor deposition (PVD). The conductivity between $\mathrm{AlSiCu}$ and $\mathrm{TiN}$ was enhanced by the inductively coupled plasma reactive ion etching process at the interface to remove the possible metal oxides generated during the fabrication process. After spin-coating the negative e-beam photoresistor (PR), the pattern of the working electrode (WE) and the counter electrode (CE) were generated by e-beam lithography to provide precise control of electrode size and shape (step 5). The patterned TiN electrodes, including WE and CE, were then exposed by wet etching (step 6). The wider width AlSiCu metal pattern underneath the TiN layer was generated by a photomask containing the pattern for the interconnections and bonding pads to connect the TiN electrodes to the bonding pad (steps 7 and 8). After etching and removing the PR, the surface of the patterned wafer was passivated by a layer of $\mathrm{Si}_{3} \mathrm{~N}_{4}$ using plasma enhanced tetraethylorthosilicate (PETEOS) method (step 9) to cover the spaces between electrodes. This $\mathrm{Si}_{3} \mathrm{~N}_{4}$ passivation could prevent the background current and enhance the electric field on the exposed surface of the 3D-NEA. Next, the surface of the wafer was planarized by the chemical-mechanical planarization (CMP) process (step 10) followed by etching the $\mathrm{Si}_{3} \mathrm{~N}_{4}$ layer to 
expose the 3D-NEA and CE, interconnections and bonding pads (step 11). The structure of the fabricated CMOS sensing chip (Figure 1D) was monitored and analyzed on the Helios Nanolab 660 Dual Beam focused ion beam (FIB) (FEI Co., Hillsboro, OR, USA) by the Integrated System Technology Inc. (Hsinchu, Taiwan).

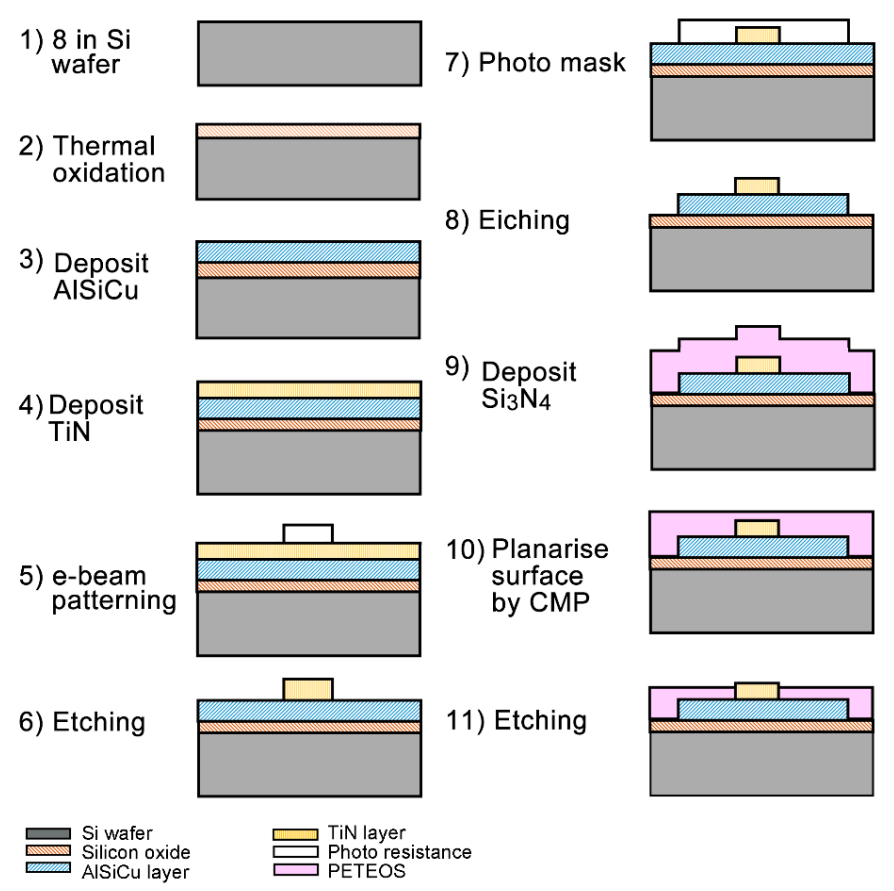

Figure 2. Fabrication procedures of standard CMOS process to construct a sensing chip with 3D-NEA.

\subsection{Apparatus and Electrochemical Measurement}

The CMOS sensing chip was fixed on a printed circuitry board (PCB) and wire bonded by the Silicon Application Corp. (Hsinchu, Taiwan) (Figure S1 in the supplementary material) to develop a TiN 3D-NEA-based sensing system, which was then connected to the CHI6116E electrochemical potentiostat (CH Instruments, Inc., Austin, TX, USA) and a personal computer to perform the electrochemical measurements. The counter electrode of the adjacent sensing unit was used as the reference electrode (RE) in the electrochemical measurements (Figure 1B). The cyclic voltammetry (CV) was performed in the phosphate buffer $\left(25 \mathrm{mM} \mathrm{Na}_{2} \mathrm{HPO}_{4}\right.$ and $25 \mathrm{mM} \mathrm{NaCl}^{\mathrm{pH}} 7.0$ ) containing $5.0 \mathrm{mM} \mathrm{Ru}\left(\mathrm{NH}_{3}\right)_{6} \mathrm{Cl}_{3}$ in a potential range between $-0.6 \mathrm{~V}$ and $+0.3 \mathrm{~V}$ versus $\mathrm{RE}$ at the scan rates of $20,50,100$, and $200 \mathrm{mV} / \mathrm{s}$. The electrochemical measurements of $\mathrm{H}_{2} \mathrm{O}_{2}$ on the TiN 3D-NEA-based sensing system at various concentrations were performed by $\mathrm{CV}$ in the phosphate buffer at the scan rate of $100 \mathrm{mV} / \mathrm{s}$ in a potential range of $-0.50 \mathrm{~V} \sim 0 \mathrm{~V}$ versus $\mathrm{RE}$.

\section{Results}

\subsection{Numeric Simulation of the Electric Field Distribution of Nano- and Micro-Electrodes}

The electric field strength and distribution of the conventional microelectrode and the proposed nano-electrode array were compared by numeric simulation via the simulator (COMSOL MULTI PHYSICS) (Figure S2). The maximum electric field $\left(4.28 \times 10^{5} \mathrm{~V} \mathrm{~m}^{-1}\right)$ of the micro-electrode with a size of $7.4 \times 7.4 \mu \mathrm{m}^{2}$ (the surface area of $5.48 \times 10^{-7} \mathrm{~cm}^{2}$ ) appeared only at four corners, while the electric field strength on the surface and at four sides of the microelectrode was minimal (Figure 3A). In comparison, the proposed $8 \times 8$ array of 3D nano-electrodes with a radius of $0.1 \mu \mathrm{m}$ and a height of $0.1 \mu \mathrm{m}$ (the estimated surface area of $9.42 \times 10^{-10} \mathrm{~cm}^{2}$ for each nano-electrode) exhibited a more evenly distributed electric field on the edge of the nano-electrode with a maximum magnitude of $2.07 \times 10^{6} \mathrm{~V} \cdot \mathrm{m}^{-1}$, which was about five times higher than that on the microelectrode (Figure 3B, inset). 
This result suggests that the electric field of the electrode can be greatly enhanced by reducing its size from micro- to nano-scale. The reduction of the surface area may not only enhance the electric field but also reduce the electric double layer impedance and the noise at the electrode/electrolyte interface $[20,40,41]$.

Interestingly, the strong electric field could be seen not only at the upper end of the 3D nano-electrode but also on its side wall (Figure 3C). Upon the simulation, about $75 \%$ of the maximal electric field strength could be retained on the side wall at $0.04 \mu \mathrm{m}$ below the upper end, whereas about $56.8 \%$ of the maximal electric field strength could be observed at the position $0.1 \mu \mathrm{m}$ below the upper end. This result suggests that more surface area on the 3D nano-electrode can be covered by the high electric field than that on the planar nano-electrodes. Accordingly, the mass transport and redox reactions of electroactive species may be facilitated on or around the 3D nano-electrodes [18].
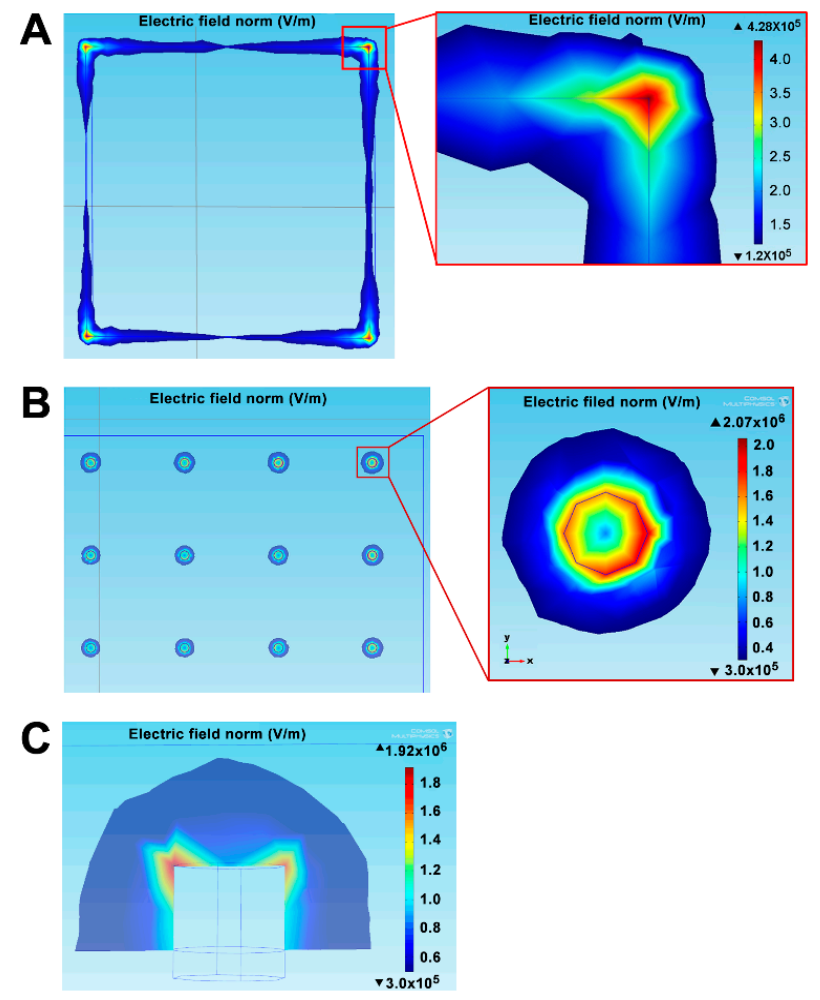

Figure 3. Simulation of electric field distribution of three different of electrodes. (A) Electric field distribution of the $7.4 \times 7.4 \mu^{2}$ microelectrode; (inset) the enlarged image of the electric field distribution at the corner of microelectrode. (B) Electric field distribution of 3D-NEA with a radius of $0.1 \mu \mathrm{m}$ and a height of $0.1 \mu \mathrm{m}$; (inset) the electric field distribution for a single nano-electrode with a radius of $0.1 \mu \mathrm{m}$. (C) The cross-section view of the electric field distribution for the 3D nano-electrode with a radius of $0.1 \mu \mathrm{m}$. These data were simulated by the COMSOL Multiphysics software (v.4.4).

\subsection{Fabrication and Characterizations of Nano-Electrode Array}

The CMOS sensing chip containing 10 sensing units (Figure 1A,D) was fabricated following a procedure flow as illustrated in Figure 2. Each sensing unit contained a 3D-NEA as the WE and a CE (Figures 1C and 4A). Each nano-electrode in the 3D-NEA exhibited the pole-like structure with a dimension of $0.1 \mu \mathrm{m}$ in radius and $35 \mathrm{~nm}$ in height (Figure 4B). The FIB image of the cross-section of a $3 \mathrm{D}$ nano-electrode showed the sequential organization of $\mathrm{Si}$ wafer, $\mathrm{SiO}_{2}, \mathrm{AlSiCu}, \mathrm{TiN}$ electrode, and $\mathrm{Si}_{3} \mathrm{~N}_{4}$ structures from the bottom to the top of the device (Figure $4 \mathrm{~B}$ ). Pt coating on the top was used to protect the surface of the sample from the cutting effect during the FIB imaging. The results indicate that the fabrication of the 3D-NEA-based CMOS sensing chip was successful. 
A

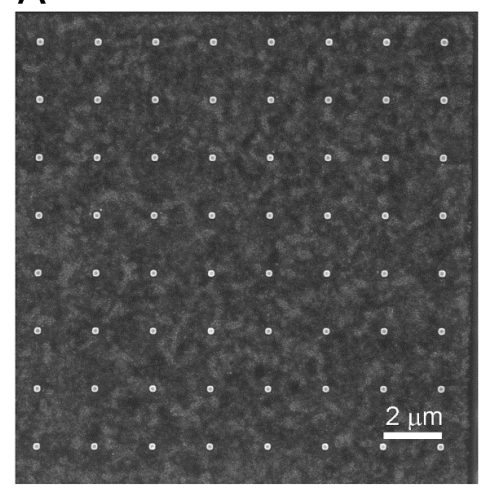

B

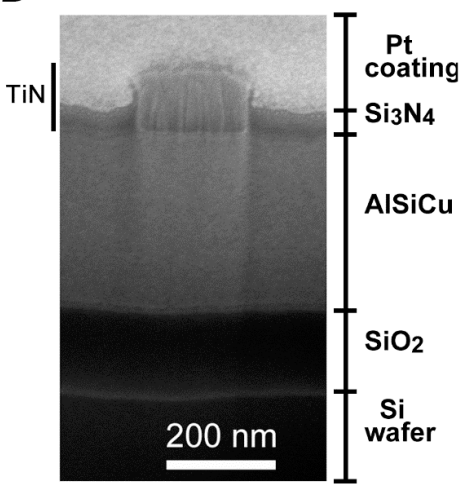

Figure 4. SEM images of 3D-NEA and the single nano-electrode. (A) The top view of 3D-NEA. (B) The focused ion beam (FIB) image of the cross section view of the nano-electrode in the 3D-NEA with a radius of $0.1 \mu \mathrm{m}$. The organization and distribution of $\mathrm{Si}$ wafer, $\mathrm{SiO}_{2}, \mathrm{AlSiCu}, \mathrm{TiN}$ electrode, and $\mathrm{Si}_{3} \mathrm{~N}_{4}$ structures in the CMOS chip are indicated on both sides.

As a control, the microelectrode with a size of $33.6 \times 8.8 \mu \mathrm{m}^{2}$ was also fabricated by the standard CMOS process (Figure 5B, inset). The center-to-center distance between nano-electrodes of the 3D-NEA (Figure 4A) was $2 \mu \mathrm{m}$. Compared to the size of the nano-electrode, the distance between adjacent electrodes was much far away, making each nano-electrode behave as an individual sensing unit. With this design, the nano-electrodes in the 3D-NEA were assumed to have their own depletion zone without overlapping with others [15,42,43].
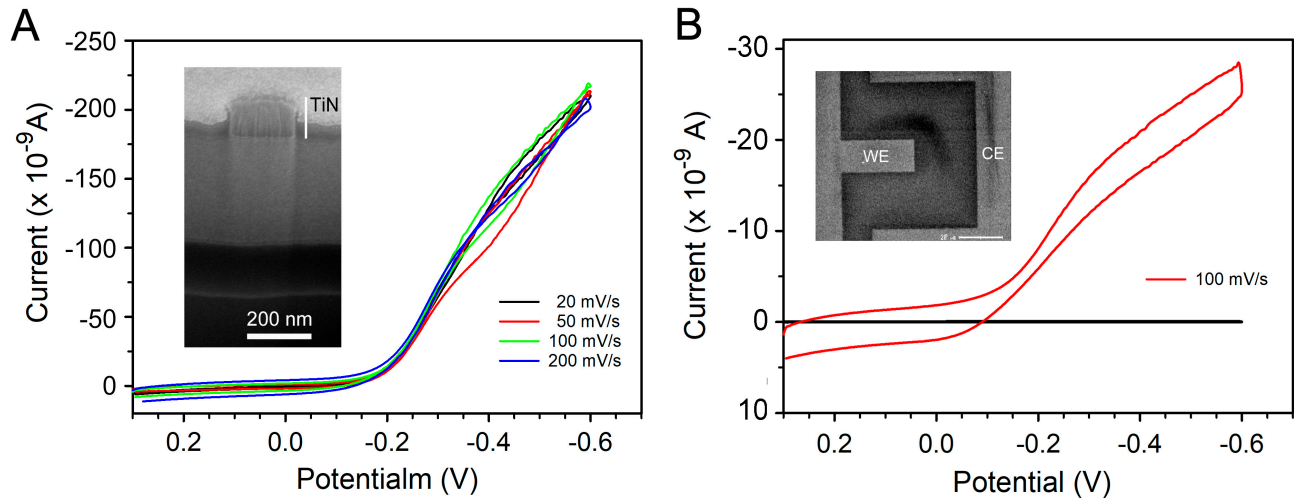

Figure 5. Cyclic voltammograms of $\mathrm{Ru}\left(\mathrm{NH}_{3}\right)_{6}{ }^{3+}$ on different electrodes. (A) $5 \mathrm{mM} \mathrm{Ru}\left(\mathrm{NH}_{3}\right)_{6}{ }^{3+}$ at 3D-NEA. (B) $5 \mathrm{mM} \mathrm{Ru}\left(\mathrm{NH}_{3}\right)_{6}{ }^{3+}$ at the microelectrode $\left(33.6 \times 8.8 \mu \mathrm{m}^{2}\right)$. The inset in each panel is the SEM image of the corresponding microelectrode or nano-electrode. The scale bar in the inset of panel (B) is $20 \mu \mathrm{m}$.

\subsection{Electrochemical Characterization of TiN 3D-NEA-Based Sensing Chip}

The electrochemical properties of the single sensing unit in the sensing chips with the 3D-NEA (the estimated total active area of $3.42 \times 10^{-8} \mathrm{~cm}^{2}$ ) and microelectrode (the estimated active area of $2.96 \times 10^{-6} \mathrm{~cm}^{2}$ ) were studied by $\mathrm{CV}$ in the presence of $5 \mathrm{mM} \mathrm{Ru}\left(\mathrm{NH}_{3}\right)_{6}{ }^{3+}$ in a potential range between $-0.6 \mathrm{~V}$ and $+0.3 \mathrm{~V}$ at the scan rates of 20,50,100, and $200 \mathrm{mV} / \mathrm{s}$. Interestingly, the cyclic voltammogram of $\mathrm{Ru}\left(\mathrm{NH}_{3}\right)_{6}{ }^{3+}$ at different scan rates (from $20 \mathrm{mV} / \mathrm{s}$ to $200 \mathrm{mV} / \mathrm{s}$ ) was nearly identical and exhibited steady state or quasi-steady state reaction curves on the sensing chip with 3D-NEA (the radius of nano-electrode $\leq 100 \mathrm{~nm}$ ) (Figure 5A) $[15,44]$. The occurrence of this phenomenon may have been due to the fast mass transport of redox couple in the diffusion layer of the 3D-NEA [11-13,15,44], presumably driven by convergent diffusion near the electrode. Under these 
circumstances, the concentration gradient of electroactive species in the diffusion layer remained high and did not deplete significantly at different scan rates.

In comparison, the $\mathrm{Ru}\left(\mathrm{NH}_{3}\right)_{6}{ }^{3+}$ exhibited a typical cyclic voltammogram on the microelectrode with a limited current response (Figure 5B), presumably due to the planar diffusion near the microelectrode $[15,42,43]$.

In addition to the electrochemical behavior, we found that the current densities obtained from two types of electrodes were inversely proportional to their surface areas (Table 1). The normalized current density of the 3D-NEA at $-0.45 \mathrm{~V}$ and scan rate of $100 \mathrm{mV} / \mathrm{s}$ was $8.02 \times 10^{5} \mathrm{~A} \mathrm{~cm} \cdot \mathrm{mol}^{-1}$, which was about two orders of magnitude higher than that calculated from the microelectrode $\left(1.69 \times 10^{3} \mathrm{~A} \cdot \mathrm{cm} \cdot \mathrm{mol}^{-1}\right)($ Table 1$)$. The high current density observed in the 3D-NEA may have resulted in part from the radial diffusion and high electric field near the electrode, leading to the enhancement of electrochemical reactivity of the redox species. The calculated current density in the 3D-NEA was about $59.0 \%$ of that in the previously reported Au nano-electrode array with a small radius [11]. It may have been due to the low conductivity of TiN, which is about one fifth that of $\mathrm{Au}$.

Table 1. The comparison of the physical and electrochemical characteristics of electrodes with different geometries.

\begin{tabular}{|c|c|c|c|}
\hline Electrodes & Electrode Radius $^{a}(\mu \mathrm{m})$ & Total Active Area ${ }^{b}\left(\mathrm{~cm}^{2}\right)$ & $\begin{array}{c}\text { Current Density } \\
\left(\mathrm{A} \cdot \mathrm{cm} \cdot \mathrm{mol}^{-1}\right)\end{array}$ \\
\hline 3D-NEA & 0.10 & $3.42 \times 10^{-8}$ & $8.02 \times 10^{5}$ \\
\hline Microelectrode & $(33.6 \times 8.8)^{c}$ & $2.96 \times 10^{-6}$ & $1.69 \times 10^{3}$ \\
\hline
\end{tabular}

\subsection{Electrochemical Measurement of $\mathrm{H}_{2} \mathrm{O}_{2}$}

$\mathrm{H}_{2} \mathrm{O}_{2}$ is one of the products of the metabolism, enzyme reactions, and biological processes in living organisms $[45,46]$. The level of $\mathrm{H}_{2} \mathrm{O}_{2}$ is often used as an indicator of the physiological and pathological conditions of the organisms $[47,48]$. Therefore, $\mathrm{H}_{2} \mathrm{O}_{2}$ is an important target in clinical diagnosis, food analysis, environmental monitoring, and drug screening. In this study, the capability of the TiN 3D-NEA-based sensing chip to detect $\mathrm{H}_{2} \mathrm{O}_{2}$ was explored. The $\mathrm{CV}$ of various concentrations of $\mathrm{H}_{2} \mathrm{O}_{2}(0.1 \mu \mathrm{M}, 1 \mu \mathrm{M}, 0.5 \mathrm{mM}, 1 \mathrm{mM}$, and $5 \mathrm{mM})$ was performed in PBS buffer with a $\mathrm{pH}$ of 7.4 in a potential range of $-0.5 \mathrm{~V} \sim 0 \mathrm{~V}$ versus $\mathrm{RE}$ at a scan rate of $100 \mathrm{mV} / \mathrm{s} . \mathrm{H}_{2} \mathrm{O}_{2}$ was found to exhibit the concentration-dependent reduction responses on the TiN 3D-NEA sensing chip (Figure 6A) with a high sensitivity $\left(667.2 \mathrm{~mA} \cdot \mathrm{cm}^{-2} \cdot \mathrm{mM}^{-1} \mathrm{H}_{2} \mathrm{O}_{2}\right)$. Besides, the electric noise of the 3D NEA chip was low (Figure 6A), and therefore the electrochemical responses of $\mathrm{H}_{2} \mathrm{O}_{2}$ could be measured by simply using the commercial potentiostat. The linear range of detection for $\mathrm{H}_{2} \mathrm{O}_{2}$ was determined between $0.1 \mu \mathrm{M}$ and $5000 \mu \mathrm{M}$ with a lowest detection limit of $0.1 \mu \mathrm{M}$ (Figure 6A, inset). Compared to other micro- or nano-electrodes reported previously, the CMOS sensing chip developed in this study exhibited higher sensitivity and a wide linear range of detection toward $\mathrm{H}_{2} \mathrm{O}_{2}$ (Table 2) $[19,20,23,49-54]$. 

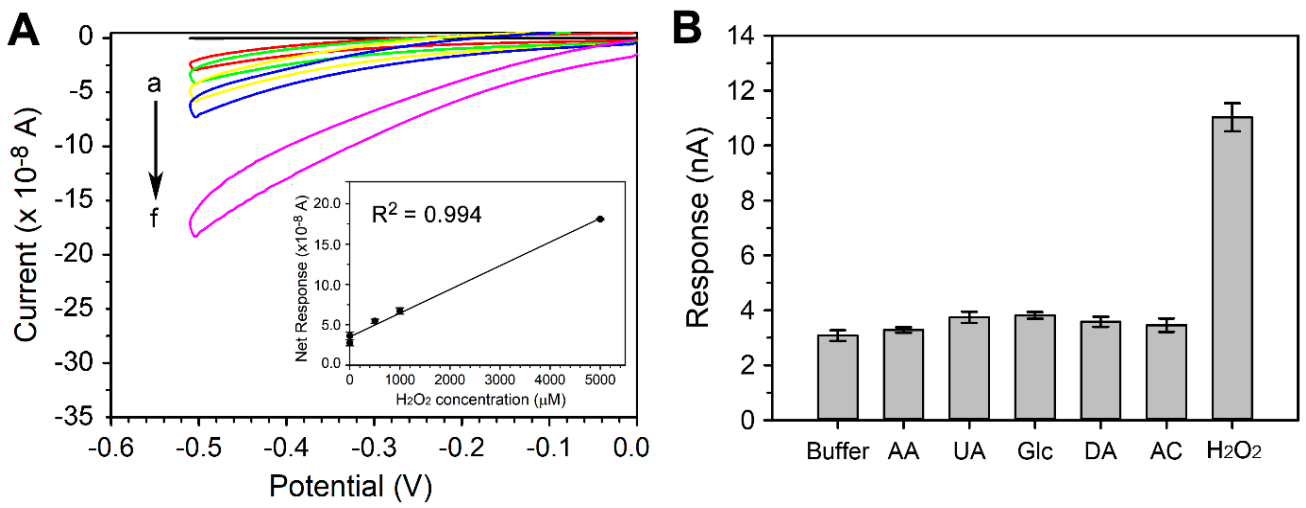

Figure 6. The electrochemical responses of $\mathrm{H}_{2} \mathrm{O}_{2}$ on CMOS sensing chip. (A) The cyclic voltammograms of various concentrations of $\mathrm{H}_{2} \mathrm{O}_{2}\left(\mathrm{a}\right.$, no $\left.\mathrm{H}_{2} \mathrm{O}_{2} ; \mathrm{b}, 0.1 \mu \mathrm{M} ; \mathrm{c}, 1 \mu \mathrm{M} ; \mathrm{d}, 500 \mu \mathrm{M}, \mathrm{e}, 1 \mathrm{mM} ; \mathrm{f}, 5 \mathrm{mM}\right)$ on sensing chip with TiN 3D-NEA. The cyclic voltammetry $(\mathrm{CV})$ was performed in a potential range of $0 \mathrm{~V} \sim-0.5 \mathrm{~V}$ at the scan rate of $100 \mathrm{mV} / \mathrm{s}$. (inset), the linear regression plot of current responses versus $\mathrm{H}_{2} \mathrm{O}_{2}$ concentrations. (B) Responses of various interferants on the 3D-NEAL. The response of different interferants including $1 \mathrm{mM}$ AA, $1 \mathrm{mM} \mathrm{UA}, 1 \mathrm{mM}$ Glucose, $1 \mathrm{mM}$ DA, $1 \mathrm{mM} \mathrm{AC}$, and $1 \mathrm{mM} \mathrm{H}_{2} \mathrm{O}_{2}$ was performed in a potential rang of $0 \mathrm{~V} \sim-0.7 \mathrm{~V}$ at a scan rate of $100 \mathrm{mV} \cdot \mathrm{s}^{-1}$. The response of these reagents at $-0.7 \mathrm{~V}$ was then recorded and analyzed. The response of the phosphate buffer solution (PBS) was used as a negative control (buffer). The data are presented as mean \pm S.D.

The detection of $\mathrm{H}_{2} \mathrm{O}_{2}$ in biological samples is usually interfered with the components in serum, such as AA, UA, DA, AC, and glucose. Hence, the electrochemical responses of these interferants were investigated on the TiN 3D-NEAL (Figure S3). The CV of $1 \mathrm{mM}$ each of AA, UA, Glucose, DA, and AC in $0.1 \mathrm{M}$ PBS, pH 7.4 was performed in a potential range of $-0.7 \mathrm{~V} \sim 0 \mathrm{~V}$ at a scan rate of $100 \mathrm{mV} / \mathrm{s}$. Subsequently, the net current response of various interferants at $-0.7 \mathrm{~V}$ was analyzed. As shown in Figure 6B, the AA, UA, Glucose, DA, and AC exhibited the electrochemical response equivalent to that of buffer only ( $3.08 \pm 0.19 \mathrm{nA})$. In comparison, the response of $1 \mathrm{mM} \mathrm{H}_{2} \mathrm{O}_{2}$ on $3 \mathrm{D}$ NEAL was $11.03 \pm 0.51 \mathrm{nA}$. This result suggests that $\mathrm{H}_{2} \mathrm{O}_{2}$ can be specifically detected on the developed CMOS sensing chip without the interference of the possible interferants in the biological samples. This characteristic is significant since the most essential challenge of non-enzymatic biosensors is to maintain the specificity that is usually conferred by enzymatic reactions.

Table 2. The comparison of the reactivity of 3D-NEA and the nanomaterial modified electrodes to $\mathrm{H}_{2} \mathrm{O}_{2}$.

\begin{tabular}{ccccc}
\hline Electrodes & $\begin{array}{c}\text { Sensitivity } \\
\left(\boldsymbol{\mu} \mathbf{A} \cdot \mathbf{m M}^{-\mathbf{1}} \cdot \mathbf{c m}^{-\mathbf{2}}\right)\end{array}$ & $\begin{array}{c}\text { Linear Range of } \\
\text { Detection }(\mathbf{m M})\end{array}$ & LOD $(\boldsymbol{\mu M})$ & Reference \\
\hline MCP/Pt/NPs & $1280-1750$ & $\sim 7$ & $9.6-17.7$ & {$[49]$} \\
PtNPs/PtME & $\mathrm{NA}$ & $0.4-800$ & 0.2 & {$[50]$} \\
$\mathrm{Cu}$ N NA/CF & 7600 & $0.0001-10$ & 0.0089 & {$[20]$} \\
Ppy/GENS/Au & 32 & $1-10$ & 300 & {$[51]$} \\
Au microelectrodes & $\mathrm{NA}$ & $100-700$ & 10 & {$[52]$} \\
AgNW & 1640 & $1.7-3.4$ & 46 & {$[53]$} \\
AgNW Array & $\mathrm{NA}$ & $0.5-5.6$ & 334 & {$[19]$} \\
Carbon fiber microelectrodes & $\mathrm{NA}$ & $2-2000$ & 2 & {$[54]$} \\
TiN NRA film with porosity & $\mathrm{NA}$ & $0.02-3$ & 20 & {$[23]$} \\
3D TiN nano-electrode array & 667200 & $0.0001-5$ & 0.1 & This work \\
\hline
\end{tabular}

LOD: limit of detection; CNT: carbon nanotube; NP: nanoparticle; MCP: micro carbon pillars; NA: nanowires array; CF: copper foam; Ppy: Polypyrrole; GENS: graphene nanosheets; NW: Nanowire; PtME: Pt micro-disk electrode; NRA: Nanorod arrays.

\section{Conclusions}

In this study, a CMOS-based electrochemical sensing chip with the TiN 3D-NEA was proposed and fabricated by a standard CMOS process. The 3D-NEA was an $8 \times 8$ array of nano-electrodes with 
a radius of $0.1 \mu \mathrm{m}$ and a spacing between electrodes of $2 \mu \mathrm{m}$. This design allowed the nano-electrode to behave as an individual sensing unit and have its own depletion zone. TiN was adopted for the electrode material because of its good chemical stability, chemical inertness, and biocompatibility. Most importantly, it could be fully integrated into the standard CMOS process with which the mass production of highly uniform, nano-scaled electrochemical sensing chips with well-defined geometry became easy. Furthermore, the 3D-NEA exhibited many electrochemical characteristics that were superior to those of conventional micro-electrodes. The CMOS sensing chip with the 3D-NEA also exhibited high sensitivity in detecting $\mathrm{H}_{2} \mathrm{O}_{2}$ and a wide linear range of detection. These results suggest that the fabricated CMOS sensing chip with the 3D-NEA exhibits great potential in the development of miniaturized, portable, and affordable biomedical devices for clinical diagnosis and POC testing in the future.

Supplementary Materials: The following are available online at http:/ / www.mdpi.com/1424-8220/19/5/994/s1, Figure S1: The CMOS sensing chip was fixed on a print circuitry board (PCB); Figure S2: Simulation of electric field distribution of microelectrode and nano-electrode array; Figure S3: The SEM imaging of the CMOS chip with 3D-NEAL.

Author Contributions: C.-J.Y. conceived the idea, designed the experiments, helped to analyze the experimental data and reviewed and edited the manuscript; C.-L.L. designed and participated in the fabrication of CMOS chip, run the experiments and prepared the original draft.

Funding: This research was funded by the research grants MOST 104-2622-M-009-002-CC2, MOST 106-2314-B-009-002 and MOST 107-2314-B-009-002 from the Ministry of Science and Technology, Taiwan.

Acknowledgments: The authors would like to thank Paul C.-P. Chao and Jeng-Tzong Sheu for instruction and valuable suggestion on the CMOS process. Special thanks also goes to the Tung Yen Lai and Min Cheng Chen of the National Nano Device Laboratories (NDL), Ministry of Science and Technology, Taiwan for fabrication of nano-electrode array chip.

Conflicts of Interest: The authors declare that there is no conflict of interest regarding the publication of this paper.

\section{References}

1. St John, A.; Price, C.P. Existing and Emerging Technologies for Point-of-Care Testing. Clin. Biochem. Rev. 2014, 35, 155-167. [PubMed]

2. Cui, G.; Yoo, J.H.; Lee, J.S.; Yoo, J.; Uhm, J.H.; Cha, G.S.; Nam, H. Effect of pre-treatment on the surface and electrochemical properties of screen-printed carbon paste electrodes. Analyst 2001, 126, 1399-1403. [CrossRef] [PubMed]

3. Gonzalez-Macia, L.; Smyth, M.R.; Morrin, A.; Killard, A.J. Enhanced electrochemical reduction of hydrogen peroxide on silver paste electrodes modified with surfactant and salt. Electrochim. Acta 2011, 56, 4146-4153. [CrossRef]

4. Lin, C.-H.; Wei, L.-Y.; Lee, J.-H.; Lien, C.-L.; Lu, C.-H.; Yuan, C.-J. Effect of anions on the oxidation and reduction of hydrogen peroxide on the gold nanoparticle-deposited carbon fiber paper electrode. Electrochim. Acta 2015, 180, 64-70. [CrossRef]

5. Wang, S.C.; Chang, K.S.; Yuan, C.J. Enhancement of electrochemical properties of screen-printed carbon electrodes by oxygen plasma treatment. Electrochim. Acta 2009, 54, 4937-4943. [CrossRef]

6. Karimian, N.; Moretto, L.M.; Ugo, P. Nanobiosensing with Arrays and Ensembles of Nano-electrode. Sensors 2016, 17, 65. [CrossRef] [PubMed]

7. Hsieh, C.H.; Dai, C.L.; Yang, M.Z. Fabrication and characterization of CMOS-MEMS magnetic microsensors. Sensors 2013, 13, 14728-14739. [CrossRef] [PubMed]

8. Liu, C.C.; Hesketh, P.J.; Hunter, G.W. Chemical Microsensors. Electrochem. Soc. Interface 2004, 13, $22-29$.

9. Qu, H. CMOS MEMS Fabrication Technologies and Devices. Micromachines 2016, 7, 1-26. [CrossRef] [PubMed]

10. Huang, X.J.; O'Mahony, A.M.; Compton, R.G. Microelectrode arrays for electrochemistry: Approaches to fabrication. Small 2009, 5, 776-788. [CrossRef] [PubMed]

11. Triroj, N.; Jaroenapibal, P.; Shi, H.; Yeh, J.I.; Beresford, R. Microfluidic chip-based nano-electrode array as miniaturized biochemical sensing platform for prostate-specific antigen detection. Biosens. Bioelectron. 2011, 26, 2927-2933. [CrossRef] [PubMed] 
12. Moretto, L.M.; Tormen, M.; De Leo, M.; Carpentiero, A.; Ugo, P. Polycarbonate-based ordered arrays of electrochemical nano-electrodes obtained by e-beam lithography. Nanotechnology 2011, 22, 185305. [CrossRef] [PubMed]

13. Sentic, M.; Virgilio, F.; Zanut, A.; Manojlovic, D.; Arbault, S.; Tormen, M.; Sojic, N.; Ugo, P. Microscopic imaging and tuning of electrogenerated chemiluminescence with boron-doped diamond nano-electrode arrays. Anal. Bioanal. Chem. 2016, 408, 7085-7094. [CrossRef] [PubMed]

14. He, R.; Chen, S.; Yang, F.; Wu, B. Dynamic Diffuse Double-Layer Model for the Electrochemistry of Nanometer-Sized Electrodes. J. Phys. Chem. B 2006, 110, 3262-3270. [CrossRef] [PubMed]

15. Norton, J.D.; White, H.S.; Feldberg, S.W. Effect of the electrical double layer on voltammetry at microelectrodes. J. Phys. Chem. 1990, 94, 6772-6780. [CrossRef]

16. Yang, X.; Zhang, G. Simulating the structure and effect of the electrical double layer at nanometre electrodes. Nanotechnology 2007, 18, 335201. [CrossRef]

17. Sánchez-Molas, D.; Esquivel, J.P.; Sabaté, N.; Muñoz, F.X.; del Campo, F.J. High Aspect-Ratio, Fully Conducting Gold Micropillar Array Electrodes: Silicon Micromachining and Electrochemical Characterization. J. Phys. Chem. C 2012, 116, 18831-18846. [CrossRef]

18. Morf, W.E.; de Rooij, N.F. Performance of amperometric sensors based on multiple microelectrode arrays. Sens. Actuators B Chem. 1997, 44, 538-541. [CrossRef]

19. Kurowska-Tabor, E.; Jaskuła, M.; Sulka, G.D. Sensitive Amperometric Sensing of Hydrogen Peroxide Using Ag Nanowire Array Electrode. Electroanalysis 2015, 27, 1968-1978. [CrossRef]

20. Wang, Z.; Cao, X.; Liu, D.; Hao, S.; Kong, R.; Du, G.; Asiri, A.M.; Sun, X. Copper-Nitride Nanowires Array: An Efficient Dual-Functional Catalyst Electrode for Sensitive and Selective Non-Enzymatic Glucose and Hydrogen Peroxide Sensing. Chem. Eur. J. 2017, 23, 4986-4989. [CrossRef] [PubMed]

21. Slaughter, G. Fabrication of nanoindented electrodes for glucose detection. J. Diabetes Sci. Technol. 2010, 4, 320-327. [CrossRef] [PubMed]

22. Wolfrum, B.; Kätelhön, E.; Yakushenko, A.; Krause, K.J.; Adly, N.; Hüske, M.; Rinklin, P. Nanoscale Electrochemical Sensor Arrays: Redox Cycling Amplification in Dual-Electrode Systems. Acc. Chem. Res. 2016, 49, 2031-2040. [CrossRef] [PubMed]

23. Xie, Z.; Liu, X.; Wang, W.; Liu, C.; Li, Z.; Zhang, Z. Fabrication of TiN nanostructure as a hydrogen peroxide sensor by oblique angle deposition. Nanoscale Res. Lett. 2014, 9, 105-109. [CrossRef] [PubMed]

24. Dong, S.; Chen, X.; Gu, L.; Zhang, L.; Zhou, X.; Liu, Z.; Han, P.; Xu, H.; Yao, J.; Zhang, X.; et al. A biocompatible titanium nitride nanorods derived nanostructured electrode for biosensing and bioelectrochemical energy conversion. Biosens. Bioelectron. 2011, 26, 4088-4094. [CrossRef] [PubMed]

25. He, X.; Hu, C.; Liu, H.; Du, G.; Xi, Y.; Jiang, Y. Building Ag nanoparticle 3D catalyst via Na2Ti3O7 nanowires for the detection of hydrogen peroxide. Sens. Actuators B Chem. 2010, 144, 289-294. [CrossRef]

26. Jiang, F.; Yue, R.; Du, Y.; Xu, J.; Yang, P. A one-pot 'green' synthesis of Pd-decorated PEDOT nanospheres for nonenzymatic hydrogen peroxide sensing. Biosens. Bioelectron. 2013, 44, 127-131. [CrossRef] [PubMed]

27. Zamfir, L.-G.; Rotariu, L.; Marinescu, V.E.; Simelane, X.T.; Baker, P.G.L.; Iwuoha, E.I.; Bala, C. Non-enzymatic polyamic acid sensors for hydrogen peroxide detection. Sens. Actuators B Chem. 2016, 226, 525-533. [CrossRef]

28. Rani, G.P.J.; Saravanan, J.; Sheet, S.; Rajan, M.A.J.; Lee, Y.S.; Balasubramani, A.; Kumar, G.G. The Sensitive and Selective Enzyme-Free Electrochemical $\mathrm{H}_{2} \mathrm{O}_{2}$ Sensor Based on rGO/ $\mathrm{MnFe}_{2} \mathrm{O}_{4}$ Nanocomposite. Electrocatalysis 2018, 9, 102-112. [CrossRef]

29. Devasenathipathy, R.; Liu, Y.-X.; Yang, C.; Kohila rani, K.; Wang, S.-F. Simple electrochemical growth of copper nanoparticles decorated silver nanoleaves for the sensitive determination of hydrogen peroxide in clinical lens cleaning solutions. Sens. Actuators B Chem. 2017, 252, 862-869. [CrossRef]

30. Yoon, Y.; Lee, G.S.; Yoo, K.; Lee, J.B. Fabrication of a microneedle/CNT hierarchical micro/nano surface electrochemical sensor and its in-vitro glucose sensing characterization. Sensors 2013, 13, 16672-16681. [CrossRef] [PubMed]

31. Liu, Y.; Wang, D.; Xu, L.; Hou, H.; You, T. A novel and simple route to prepare a Pt nanoparticle-loaded carbon nanofiber electrode for hydrogen peroxide sensing. Biosens. Bioelectron. 2011, 26, 4585-4590. [CrossRef] [PubMed]

32. Avasarala, B.; Haldar, P. Electrochemical oxidation behavior of titanium nitride based electrocatalysts under PEM fuel cell conditions. Electrochim. Acta 2010, 55, 9024-9034. [CrossRef] 
33. Yuan-Lung, C.; Jung-Chuan, C.; Zhen-Ce, L.; Tai-Ping, S.; Wen-Yaw, C.; Shen-Kan, H. Titanium Nitride Membrane Application to Extended Gate Field Effect Transistor pH Sensor Using VLSI Technology. Jpn. J. App. Phys. 2001, 40, 6311-6315.

34. Hyde, G.K.; McCullen, S.D.; Jeon, S.; Stewart, S.M.; Jeon, H.; Loboa, E.G.; Parsons, G.N. Atomic layer deposition and biocompatibility of titanium nitride nano-coatings on cellulose fiber substrates. Biomed. Mater. 2009, 4, 025001-025010. [CrossRef] [PubMed]

35. Piippo, J.; Elsener, B.; Böhni, H. Electrochemical characterization of TiN coatings. Surf. Coat. Technol. 1993, 61, 43-46. [CrossRef]

36. Nunes Kirchner, C.; Hallmeier, K.H.; Szargan, R.; Raschke, T.; Radehaus, C.; Wittstock, G. Evaluation of Thin Film Titanium Nitride Electrodes for Electroanalytical Applications. Electroanalysis 2007, 19, 1023-1031. [CrossRef]

37. Katsuhiro, Y.; Kazuhiro, N.; Tomohiko, K.; Katsuhisa, M.; Masami, O. Resistivities of titanium nitride films prepared onto silicon by an ion beam assisted deposition method. J. Phys. D Appl. Phys. 2004, 37, 1095-1101.

38. Stamenkovic, V.R.; Fowler, B.; Mun, B.S.; Wang, G.; Ross, P.N.; Lucas, C.A.; Marković, N.M. Improved Oxygen Reduction Activity on Pt3Ni(111) via Increased Surface Site Availability. Science 2007, 315, 493-498. [CrossRef] [PubMed]

39. Bilić, A.; Reimers, J.R.; Hush, N.S. Adsorption of Pyridine on the Gold (111) Surface: Implications for "Alligator Clips" for Molecular Wires. J. Phys. Chem. B 2002, 106, 6740-6747. [CrossRef]

40. Menon, V.P.; Martin, C.R. Fabrication and Evaluation of Nano-electrode Ensembles. Anal. Chem. 1995, 67, 1920-1928. [CrossRef]

41. Zoski, C.G.; Yang, N.; He, P.; Berdondini, L.; Koudelka-Hep, M. Addressable Nano-electrode Membrane Arrays: Fabrication and Steady-State Behavior. Anal. Chem. 2007, 79, 1474-1484. [CrossRef] [PubMed]

42. Wei, D.; Bailey, M.J.; Andrew, P.; Ryhanen, T. Electrochemical biosensors at the nanoscale. Lab Chip 2009, 9, 2123-2131. [CrossRef] [PubMed]

43. Armstrong, F.A.; Bond, A.M.; Hill, H.A.O.; Oliver, B.N.; Psalti, I.S.M. Electrochemistry of cytochrome c, plastocyanin, and ferredoxin at edge- and basal-plane graphite electrodes interpreted via a model based on electron transfer at electroactive sites of microscopic dimensions in size. J. Am. Chem. Soc. 1989, 111, 9185-9189. [CrossRef]

44. Arrigan, D.W. Nano-electrodes, nano-electrode arrays and their applications. Analyst 2004, 129, 1157-1165. [CrossRef] [PubMed]

45. Gerlache, M.; Senturk, Z.; Quarin, G.; Kauffmann, J.-M. Electrochemical behavior of $\mathrm{H}_{2} \mathrm{O}_{2}$ on gold. Electroanalysis 1997, 9, 1088-1092. [CrossRef]

46. Ismail, S.Z.; Khandaker, M.M.; Mat, N.; Boyce, A.N. Effects of hydrogen peroxide on growth, development and quality of fruits: A review. J. Agron. 2015, 14, 331-336.

47. Halliwell, B. Reactive species and antioxidants. Redox biology is a fundamental theme of aerobic life. Plant Physiol. 2006, 141, 312-322. [CrossRef] [PubMed]

48. Millare, B.; O’Rourke, B.; Trayanova, N. Cell-Wide Coordination of ROS-Induced ROS Release by Hydrogen Peroxide in Mitochondrial Networks. Biophys. J. 2014, 106, 183a. [CrossRef]

49. Su, J.; Gao, F.; Gu, Z.; Pien, M.; Sun, H. A novel 3-D fabrication of platinum nanoparticles decorated micro carbon pillars electrode for high sensitivity detection of hydrogen peroxide. Sens. Actuators B Chem. 2013, 181,57-64. [CrossRef]

50. Wang, J.; Zhou, M.; Dong, R.; Cong, X.; Zhang, R.; Wang, X. Simultaneous Determination of Peroxide Hydrogen and Ascorbic Acid by Capillary Electrophoresis with Platinum Nanoparticles Modified Micro-disk Electrode. Electroanalysis 2017, 29, 2483-2490. [CrossRef]

51. Yu, Y.; Chen, J.; Zhou, J. In Enzyme-free electroreduction of hydrogen peroxide at polypyrrole/graphene/au microelectrode based on three-electrode-system array. In Proceedings of the 2013 13th IEEE International Conference on Nanotechnology (IEEE-NANO 2013), Beijing, China, 5-8 August 2013; pp. 1067-1070.

52. Wang, J.; Escarpa, A.; Pumera, M.; Feldman, J. Capillary electrophoresis-electrochemistry microfluidic system for the determination of organic peroxides. J. Chromatogr. A 2002, 952, 249-254. [CrossRef] 
53. Lee, J.H.; Huynh-Nguyen, B.-C.; Ko, E.; Kim, J.H.; Seong, G.H. Fabrication of flexible, transparent silver nanowire electrodes for amperometric detection of hydrogen peroxide. Sens. Actuators B Chem. 2016, 224, 789-797. [CrossRef]

54. Sanford, A.L.; Morton, S.W.; Whitehouse, K.L.; Oara, H.M.; Lugo-Morales, L.Z.; Roberts, J.G.; Sombers, L.A. Voltammetric Detection of Hydrogen Peroxide at Carbon Fiber Microelectrodes. Anal. Chem. 2010, 82, 5205-5210. [CrossRef] [PubMed]

2019 by the authors. Licensee MDPI, Basel, Switzerland. This article is an open access article distributed under the terms and conditions of the Creative Commons Attribution (CC BY) license (http://creativecommons.org/licenses/by/4.0/). 